\title{
Smart Parking Guidance Using Optimal Cost Function
}

\author{
Mohamed S. Farag ${ }^{1}$, M. M. Mohie El Din ${ }^{1} \&$ H. A. El Shenbary ${ }^{1}$ \\ ${ }^{1}$ Department of Mathematics, Faculty of Science Al-Azhar University, Egypt \\ Correspondence: Mohamed S. Farag, Department of Mathematics, Faculty of Science, Al-Azhar University, Nasr \\ city, 11884, Cairo, Egypt. Tel: 20-1006-574-243. E-mail: mohamed.s.farag@azhar.edu.eg
}

Received: October 21, 2016

Accepted: November 18, $2016 \quad$ Online Published: February 1, 2017

doi:10.5539/cis.v10n1p48

URL: http://dx.doi.org/10.5539/cis.v10n1p48

\begin{abstract}
The industrialization of the world, increase in population and mismanagement of the available parking space has resulted in parking problems. There is a need for an intelligent and reliable system which can be used for searching the unoccupied parking facility, to reduce the cost of leasing people and for better use of resources for car-park owners. This paper introduces an algorithm to increase the efficiency of the current smart-parking system. The main objective of this algorithm is helping users automatically to find an unoccupied parking lot with least cost based on a new performance metrics to calculate the parking cost. Considering the distance between the User and Parking, Distance between Parking and services area, Percent of free spaces in each car park and Cost of parking for a time t. Matlab software was used to compute the cost function and to save an optimal parking space upon a request by the user. The experimental results show that the proposed cost function helps improve the probability of optimal parking with least cost.
\end{abstract}

Keywords: smart parking, Internet of Things, cost function, Intelligent Transportation Systems

\section{Introduction}

The industrialization of the world, slowdown city development, increase in population and mismanagement of the free parking lots has resulted in parking problems. There is a need for an intelligent and reliable sys-tem which can be used for searching the unoccupied parking facility. Smart Parking System is a part of an Intelligent Transportation Systems (ITS) (Faheem, Mahmud, Khan \& Zafar, 2013). Nowadays, the general method of finding a free parking lot is manual where the user usually finds a space in the street depending on luck and experience. This process waste effort, time and may lead to the worst case of parking failure. The aforementioned reasons encourage the user to find a predefined car park with high capacity, but this is not a preferred solution. In the last decades, a lot of researches were made in this point in order to solve the problem of parking management. The design smart parking system was introduced and implemented trying to solve the parking problem (Shiyao, Ming, Chen \& Na, 2014). This system is com-posed of ZigBee network, which sent pressure information to $\mathrm{PC}$ through a coordinator and then update database. The application use internet to get the parking information, and use advantages of Web service to gather all the scattered parking information to bring convenience to the user who want to get a parking position. An Intelligent Parking Assistant (IPA) architectural model developed in (Barone, Giur, Siniscalchi, Morgano \& Tesoriere, 2014). In this IPA the only authorized users can reserve a parking space. For users to be authorized, they should register on the IPA website. A parking lot is shown as reserved for a period (for ex. 20 mins). If the authorised user did not arrive at the given period, he will be informed that reservation is expired and this parking lot is shown as free parking lot. Parking guidance information systems were provided to minimize parking search traffic by dynamically monitoring avail-able parking and directing drivers to a vacant parking spot. An intelligent parking management system using wireless sensor networks was developed in (Tang, Zheng \& Cao, 2006). The wireless sensors were deployed into a car park space to detect and show the occupation of a parking lot. The data collected by the sensors were sent periodically to a database. This database is used for finding vacant parking lots and knowing occupation rate which can generate statistic reports about the parking status. Due to the lake of space, a lot of research tends to a multi-level parking idea. A multi-level parking is introduced as a building with number of floors for the cars to be parked. A multi-level parking can serve a lot of cars in a limited space. In (Reza, Ismail, Rokoni \& Sarkar, 2012), authors constructed a prototype of a multi-level parking assistance system based on the facility of image processing techniques. Image processing was used for detecting car plate numbers. Template matching method was used in order to recognize plate characters. After recognizing plate numbers, it is 
compared with the list of plate numbers in the system database. The authors in (Bonde, Shende, Gaikwad, Kedari \& Bhokre, 2014) aims to minimize the human intervention in parking by automating the process of car parking. They proposed a design of an Automated Parking System commanded by an Android application to organize the number of cars to be parked. There is two sub architectures (Car Control Unit and Parking Control Unit). The Parking Control Unit is commanded by the Android device having the Android application. The Parking unit is responsible for the movement of the car. Multi-level smart parking system architecture was proposed in (Ismail, Reza, Rokoni \& Sarkar, 2012; Rokoni, Ismail, Reza \& Sarkar, 2011). An image processing techniques also introduced to monitor and identify the vehicles. They used Optical character recognition (OCR) to identify the illegal cars. OCR is the electronic translation of scanned images of typewritten, handwritten or printed text into machine text. OCR is widely used to convert books and documents into electronic les. The OCR technique has several steps like enhancement, segmentation, feature extraction and classification (Lotufo, Morgan \& Johnson, 1990; Tavsanoglu \& Saatci, 2000). The concept of Internet of Things (IoT) begins with things which have identity communication devices. This de-vices could be controlled, or monitored using computers connected through internet (Khanna \& Anand, 2016). A smart parking system using IoT to reduce parking hazards and helps to minimize emitting greenhouse gases, increase the security of these smart parking (Ramaswamy, 2016; Juliadotter, 2016). IoT enables smart parking system using the system of interconnected Distance Sensor, Pi Camera devices together. This hardware were used in collecting data and transmit it to cloud storage, to enable commuters to get a parking lot in less time to save fuel and ultimately producing excessive $\mathrm{CO} 2$ emission. In (Mainetti, Palano, Patrono, Stefanizzi \& Vergallo, 2014), authors present a heterogeneous network of the integration of Ultra-High Frequency (UHF) Radio, Frequency Identification (RFID) and IEEE 802.15.4 Wireless Sensor Network (WSN) devices which can be deployed in any outdoor parking. This System could collect information from the parking like occupancy of the parking lots and guide the driver to the nearest vacant space. Also, the application has an NFC-based e-wallet system enabling users to pay for the parking fee. The remainder of this paper is organized as follows. Section 2 outlines the architecture of the proposed smart parking system. Section 3 presents the experimental results. Finally, conclusion and future work are given in Section 4.

\section{Proposed Method}

This paper present a parking system architecture based on the least cost function. A mathematical model for the system operation is delivered. The system aimed to guide the user for an optimal parking space with least cost. Figure 1 show the design of the parking area surrounded by service places and streets.

There exist 4 gates for entrance, 4 gates for exit, 4 parking places and 10 services area. Matrix A denote the distance between the Entrance Gates $G_{-} i$ and the parking places $p_{-} j$

$$
A=\left(\begin{array}{llll}
4 & 6 & 6 & 2 \\
2 & 4 & 6 & 6 \\
6 & 2 & 4 & 6 \\
6 & 6 & 2 & 4
\end{array}\right)
$$

and the matrix $B$ define the distance between the parking place $P_{-} i$ and Service area $S_{-} j$.

$$
B=\left(\begin{array}{llllllllll}
4 & 4 & 8 & 8 & 7 & 7 & 4 & 3 & 3 & 3 \\
7 & 3 & 3 & 7 & 6 & 2 & 2 & 2 & 6 & 3 \\
8 & 8 & 3 & 4 & 3 & 2 & 2 & 5 & 5 & 3 \\
4 & 7 & 7 & 3 & 2 & 6 & 3 & 5 & 2 & 2
\end{array}\right)
$$






Figure 1. Architecture of Parking

Figure 2 show what happen when a new car reach an entrance gate. If a new car arrives at an entrance gate, the user should sent information to the system in order to get the optimal parking. The User sends the entrance gate number and the service number which he will go to it after parking.

The system collects this information and then computes the cost function to get the optimal parking number. After the system guide the user to the optimal parking according to least cost function, the system update the parking expected number.

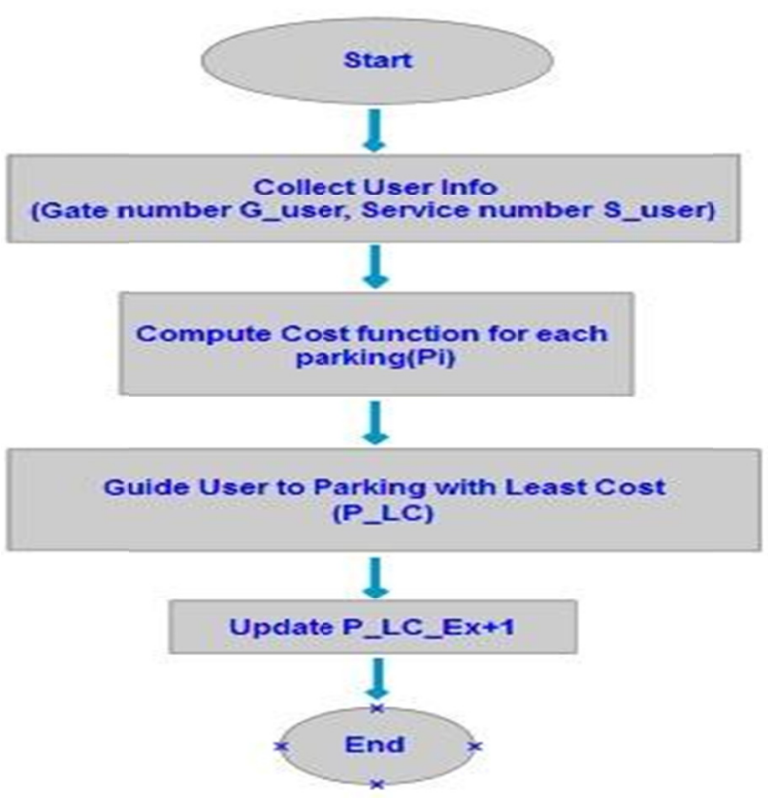

Figure 2. Steps of Collecting Data at Parking Entrance 
The proposed Cost function,

$$
\text { Cost_ } P_{i}=a_{1} * D\left(G \text { User; } P_{i}\right)+a 2 * D\left(P_{i} ; S_{-} \text {User }\right)+a 3 *\left(n \_P_{i}\right)+a 4 *\left(P_{i} * \text { cost }\right) \text {. }
$$

where Cost $P_{i}$ is the cost of the User parking in Parking number $i$,

$\mathrm{D}\left(\mathrm{G}_{-}\right.$User; $\left.\mathrm{P}_{\mathrm{i}}\right)$ is the distance between the user entrance gate and the parking number $\mathrm{i}, \mathrm{D}\left(\mathrm{P}_{\mathrm{i}}, \mathrm{S}_{-}\right.$User $)$is the distance between the parking number $i$ and the user service place, $\mathrm{n}_{-} \mathrm{P}_{\mathrm{i}}$ is the number of free slots in the parking number $i$ and $P_{i_{-}}$cost is the cost of money of the parking number $i . a_{1}, a_{2}, a_{3}$ and $a_{4}$ are parameters which can be defined according to experimental results. After computing the cost function for all Parking places, the user is guided to the

parking which has the minimum cost. Figure 3 is a flow chart that views how to get the optimal parking according to the given Cost function equation.

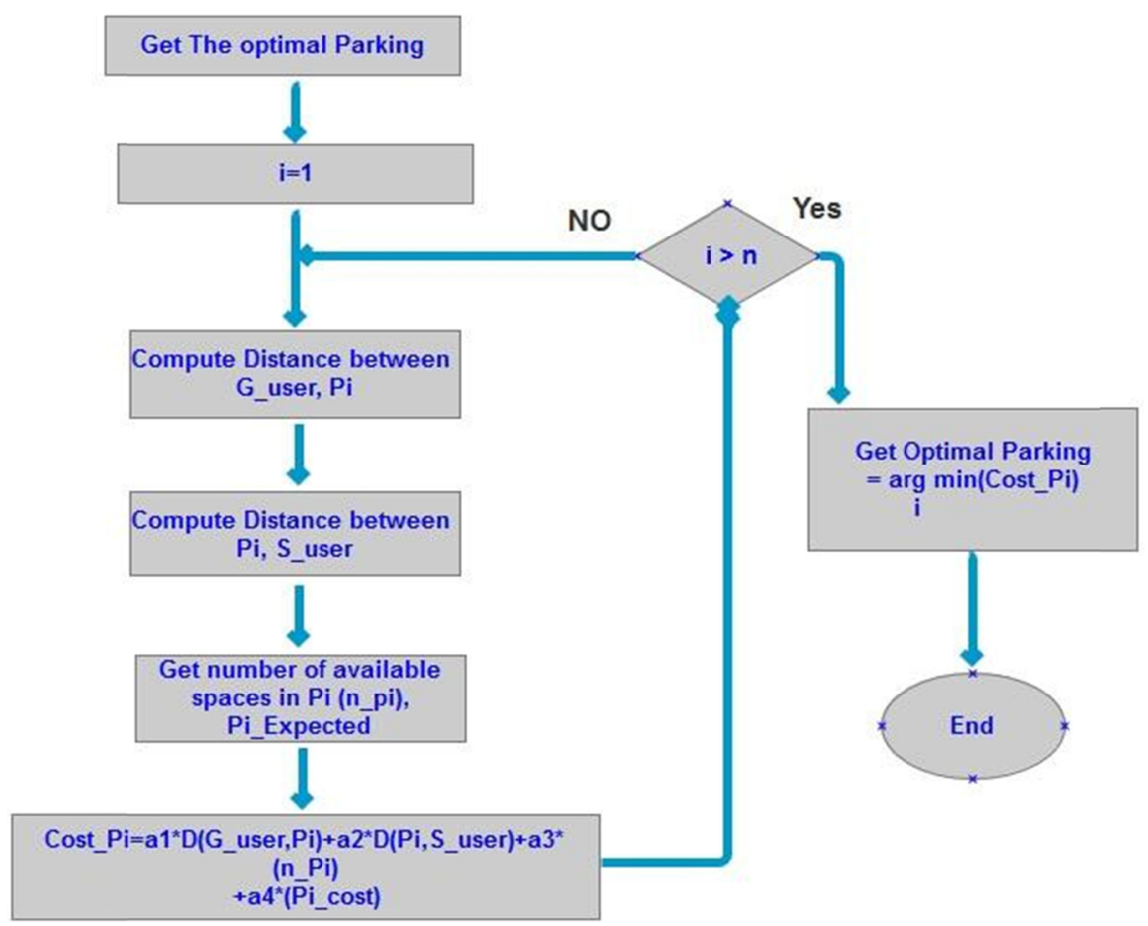

Figure 3. Flow chart of computing Least Cost Function

\section{Experimental Results and Discussion}

In order to view the efficiency of the proposed method, Matlab was used for setup the model and simulate the parking system. We determined the parameter of the system execution as the cost function. If we minimized this cost, we will reduce the other costs like fuel, monetary, distance the user walk, traffic congestion and environmental pollution costs. An optimal cost value reach to a good system performance. The parameters with the least cost value will be considered as the optimal solution and will be used as a proposal to apply a similar model indeed. In the simulation, we used 100, 200, 300, 400, and 500 cars that arrived at the parking. Both the inter-arrival time

of cars and the time which car spent in the parking were randomly selected. In (HAM, TSAI, Nguyen, Dow \& Deng, 2015) the author did not use the percent of free parking spaces in the cost function, which leads them to introduce a method for forwarding the vehicle to another parking if the current parking is full. We think it must not allow the user to reach a full park. The system must guide the user to the correct park (park with free space) at first time, So we introduce the cost function depends in to 4 parameters. We added the parameter of Percent of free spaces in the parking, and the cost of the parking. Also, if any Parking is full, we make the cost function of this parking equal infinity, in order not to guide the user to a full parking. Now there exist 4 car parks with the capacities $\mathrm{P}_{1}=120$ spaces, $\mathrm{P}_{2}=170, \mathrm{P}_{3}=200, \mathrm{P}_{4}=120, \mathrm{P}_{1}$ cost $=7, \mathrm{P} 2$ cost $=5, \mathrm{P}_{3}$ cost $=9$ and $\mathrm{P}_{4} \_$cost $=10$. The Cost Function depends on 4 parameters $\left(a_{1}, a_{2}, a_{3}\right.$ and $\left.a_{4}\right)$. We make a lot of experiments, to determine the optimal parameter values, which make the cost function value smaller as much as possible. These parameters subject to the equation 


$$
\mathrm{a}_{1}+\mathrm{a}_{2}+\mathrm{a}_{3}+\mathrm{a}_{4}=\text { Constant: }
$$

Table 1 show the result of some experiments in case of 100 cars served. The cost function is determined according to different parameter values. The parameter value $(2,5,1$, and 2$)$ gives least cost.

Table 1. Effect of Parameters value on Cost Function in case of 100 cars served

\begin{tabular}{rrrrrr}
\hline $\mathrm{a}_{1}$ & $\mathrm{a}_{2}$ & $\mathrm{a}_{3}$ & $\mathrm{a}_{4}$ & Number of cars served & Average Cost func-tion value \\
\hline 3 & 3 & 3 & 1 & 100 & 6.771 \\
5 & 2 & 1 & 2 & 100 & 6.847 \\
2 & 5 & 1 & 2 & 100 & 6.533 \\
3 & 3 & 1 & 3 & 100 & 7.4183 \\
\hline
\end{tabular}

Table 2 show the result of some experiments in case of 300 cars served. The parameters values were changed, it is shown that parameter value $(2,5,1$, and 2$)$ gives least cost.

Table 2. Effect of Parameters value on Cost Function in case of 300 cars served

\begin{tabular}{rrrrrr}
\hline $\mathrm{a}_{1}$ & $\mathrm{a}_{2}$ & $\mathrm{a}_{3}$ & $\mathrm{a}_{4}$ & Number of cars served & Average Cost func-tion value \\
\hline 3 & 3 & 3 & 1 & 300 & 6.672 \\
5 & 2 & 1 & 2 & 300 & 6.920 \\
2 & 5 & 1 & 2 & 300 & 6.352 \\
2 & 2 & 4 & 2 & 300 & 7.3097 \\
\hline
\end{tabular}

Table 3 show the result of some experiments in case of 500 car served. The parameters values were changed, it is shown that parameter value $(2,5,1$, and 2$)$ gives least cost.

Table 3. Effect of Parameters value on Cost Function in case of 500 cars served

\begin{tabular}{rrrrrr}
\hline $\mathrm{a}_{1}$ & $\mathrm{a}_{2}$ & $\mathrm{a}_{3}$ & $\mathrm{a}_{4}$ & Number of cars served & Average Cost func-tion value \\
\hline 3 & 3 & 3 & 1 & 500 & 6.672 \\
5 & 2 & 1 & 2 & 500 & 6.920 \\
2 & 5 & 1 & 2 & 500 & 6.352 \\
2 & 2 & 4 & 2 & 500 & 7.3097 \\
\hline
\end{tabular}

Table 4. Least Cost Function in different numbers of car parking

\begin{tabular}{rrrrrr}
\hline $\mathrm{a}_{1}$ & $\mathrm{a}_{2}$ & $\mathrm{a}_{3}$ & $\mathrm{a}_{4}$ & Number of cars served & Average Cost func-tion value \\
\hline 2 & 5 & 1 & 2 & 100 & 6.533 \\
2 & 5 & 1 & 2 & 200 & 6.407 \\
2 & 5 & 1 & 2 & 300 & 6.352 \\
2 & 5 & 1 & 2 & 400 & 6.386 \\
2 & 5 & 1 & 2 & 400 & 6.331 \\
\hline
\end{tabular}

Table 4 show the best parameter values that increase the average cost function in different cases on number of cars served. After a lot of experiments on different value of parameters and from the above results, it is clear that the value $\left(a_{1}=2 ; a_{2}=5 ; a_{3}=1 ; a_{4}=2\right)$ minimize the cost function to the optimal value.

\section{Conclusion and Future Work}

In this paper we proposed a method to improve performance of the parking process. This method depended on minimizing the cost function, which reduce the cost of moving to the parking space, cost of moving from parking to destination service and monetary to pay. The proposed architecture has been successfully simulated. The results show that our method significantly reduces the average cost value. The simulation of our system is considered as an optimal solution when most of the vehicles successfully found a free parking space with least cost. In our future study, we will use image processing techniques in order to detect free slots and car plate number to increase the security of our system. 


\section{References}

Barone, R. E., Giur, T., Siniscalchi, S. M., Morgano, M. A., \& Tesoriere, G. (2014). Architecture for parking management in smart cities, Insti-tution of Engineering and Technology(IET). Intelligent Transportation System, 8(5), 445-452.

Bonde, D. J., Shende, R. S., Gaikwad, K. S., Kedari, A. S., \& Bhokre, A. U. (2014). Automated car parking system commanded by android application. International Journal of Computer Science and Information Technologies (IJCSIT), 5(3), 3001-3004.

Faheem, S. A., Mahmud, G. M., Khan, M. R., \& Zafar, H. (2013). A survey of intelligent car parking system. Journal of Applied Research and Technology, 11, 714-726.

Ham, T. H., Tsai, M., Nguyen, D. B., Dow, C., \& Deng, D. (2015). A cloud-based smart-parking system based on internet of things technologies. The journal for rapid open access publishing, 3, 1581-1591.

Ismail, M. F., Reza, M. O., Rokoni, A. A., \& Sarkar, M. A. R. (2012). Design and development of an advanced vehicle parking system. International Conference on Informatics. Electronics and Vision (ICIEV) IEEE, 458- 463.

Juliadotter, N. V. (2016). Hacking smart parking meters, International Confer-ence on Internet of Things and Applications (IoTA), Maharashtra Institute of Technology, Pune, India,191-196.

Khanna, A., \& Anand, R. (2016). Iot based smart parking system, International Conference on Internet of Things and Applications (IoTA),Maharashtra Institute of Technology, Pune, India, 266-270.

Lotufo, R. A., Morgan, A. D., \& Johnson, A. S. (1990). Automatic number plate recognition, Inst. Elect. Eng. Colloquium on Image Analysis for Transport Applications, 1- 6.

Mainetti, L., Palano, L., Patrono, L., Stefanizzi, M. L., \& Vergallo, R. (Sept. 2014). Integration of rfid and wsn technologies in a smart parking system, 22nd International Conference on Software, Telecommunications and Computer Networks (SoftCOM), 104-110.

Ramaswamy, P. (2016). Iot smart parking system for reducing green house gas emission, Fifth International Conference on Recent Trends in Information Technology, IEEE, 1-6.

Reza, M. O., Ismail, M. F., Rokoni, A. A., \& Sarkar, M. A. R. (2012). Smart parking system with image processing facility. International Journal of Intelligent Systems and Applications, 3, 41-47.

Rokoni, A. A., Ismail, M. F., Reza, M. O., \& Sarkar, M. A. R. (2011). De-velopment of an image processing based container traff control system, International Conference on Mechanical, Automotive and Aerospace Engineering-ICMAA, 10-13.

Shiyao, C., Ming, W., Chen, L., \& Na, R. (2014). The research and implement of the intelligent parking reservation management system based on zigbee technology. IEEE Sixth International Conference on Measuring Technology and Mechatronics Automation, 741-744.

Tang, V., Zheng, Y., \& Cao, J. (2006). An intelligent car park management system based on wireless sensor networks. International Symposium on Pervasive Computing and Applications, 65-70.

Tavsanoglu, V., \& Saatci, E. (2000). Feature extraction for character recog-nition using gabor-type filters implemented by cellular neural networks. IEEE International Workshop on Cellular Neural Networks and their Applications, IEEE, 63-68.

\section{Copyrights}

Copyright for this article is retained by the author(s), with first publication rights granted to the journal.

This is an open-access article distributed under the terms and conditions of the Creative Commons Attribution license (http://creativecommons.org/licenses/by/4.0/). 